\title{
РОЛЬ ЭЛЕКТРОЛИТНОГО ОБМЕНА В ПАТОГЕНЕТИЧЕСКИХ МЕХАНИЗМАХ ПРИ МИОТОНИИ ТОМСЕНА
}

\author{
${ }^{1}$ Гасанов Х.И.*, ${ }^{2}$ Алиева Д.М., ${ }^{3}$ Кулиев М.Р. \\ ${ }^{1}$ Республиканская клиническая больница им. акад. М.А. Мир-Касимова, Баку \\ ${ }^{2}$ Азербайджанский Медищинский Университет, Баку
}

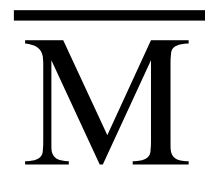

иотония Томсена относится к группе сравнительно редких наследственных нервно-мышечных заболеваний, основным клиническим проявлением которых является миотонический тип нарушения движений или миотонический феномен, заключающийся в затруднении расслабления мышцы после еe произвольного сокращения.

Следует отметить, что многие вопросы, касающиеся этиологии, клиники, патоморфологии и генетики миотонии Томсена разрешены. Вместе с тем вопросы патогенетических механизмов двигательных нарушений остаются не до конца выясненными, а мнения исследователей в этом направлении различны.

В последние годы некоторые авторы причину патологических изменений, возникающих при миотониях, объясняют ускоренным образованием свободных радикалов кислорода в организме [4,10].

Образующиеся в процессе утилизации кислорода активные интермедиаты, являясь главной причиной токсичности кислорода, ускоряют процессы пероксидации липидов в клеточной мембране и тем самым оказывают повреждающее действие на клеточную мембрану $[1,2,7]$. Наряду с этим имеются сведения, что при миотонии Томсена одним из наиболее реальных механизмов патогенеза нарушений можно считать изменения физико-химических свойств биомембраны и нарушение проницаемости их для электролитов [6]

Исходя из вышеизложенного, целью нашей работы явилось выявление характера изменений некоторых показателей электролитного обмена в крови больных мио*email: doctorxanlar@yahoo.com тонией Томсена в зависимости от тяжести и длительности заболевания.

Изучение электролитного обмена производилось путем определения содержания в плазме крови 40 больных миотонией Томсена кальция (Ca2+), хлора (Сл - ), натрия $(\mathrm{Ha}+)$ и калия $(\mathrm{K}+)$. Концентрация кальция в плазме крови определялась калориметрическим методом, хлориды определялись фотометрическим методом, а концентрации натрия и калия определяли методом плазменной фотометрии. Контрольную группу составили 54 здоровых человека по полу и возрасту соответствующие исследуемой группе больных. К легкой степени заболевания были отнесены 12 больных, к средней степени - 17 и к тяжелой степени - 11 больных.

По длительности заболевания больные были распределены следующим образом: до 10 лет - 7 больных, от 10 до 19 лет - 6 больных, 20-29 лет - 12 больных, 30-39 лет 7 больных и более 40 лет - 8 больных.

Полученные результаты показали, что характер изменения содержания натрия, калия, кальция и хлоридов в сыворотке крови больных зависит от степени тяжести заболевания (рис.1). Как видно из представленных данных, в сыворотке крови больных с различной степенью тяжести заболевания количество хлора не изменяется, в то время как количество калия статистически возрастает. Так, при легкой степени заболевания показатели калия относительно контрольной группы увеличены на 7,4\%, при средней степени тяжести на $13,1 \%$, при тяжелой степени на 16,3\%.

При легкой и средней степени тяжести миотонии Томсена наблюдается увеличение 

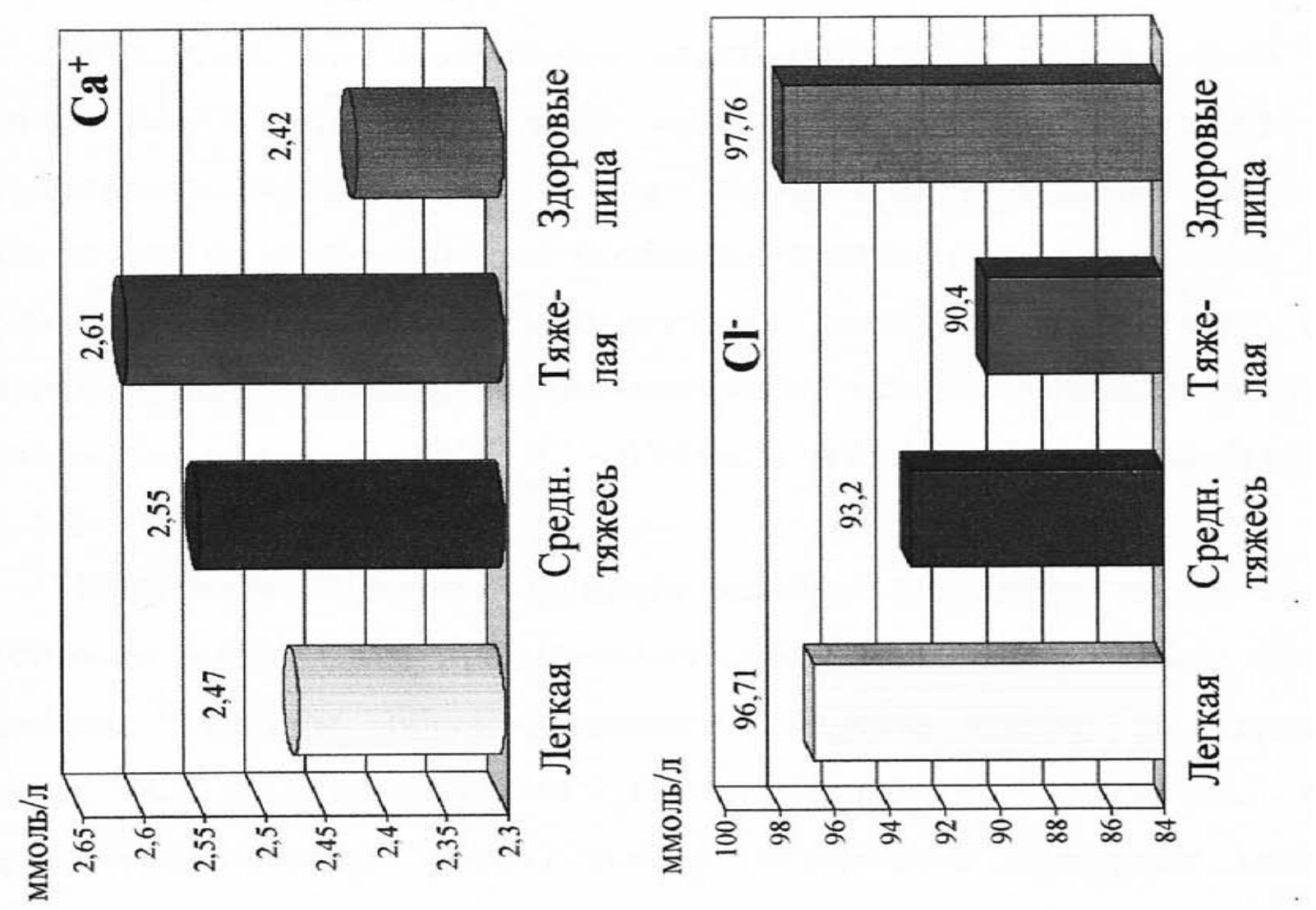

政
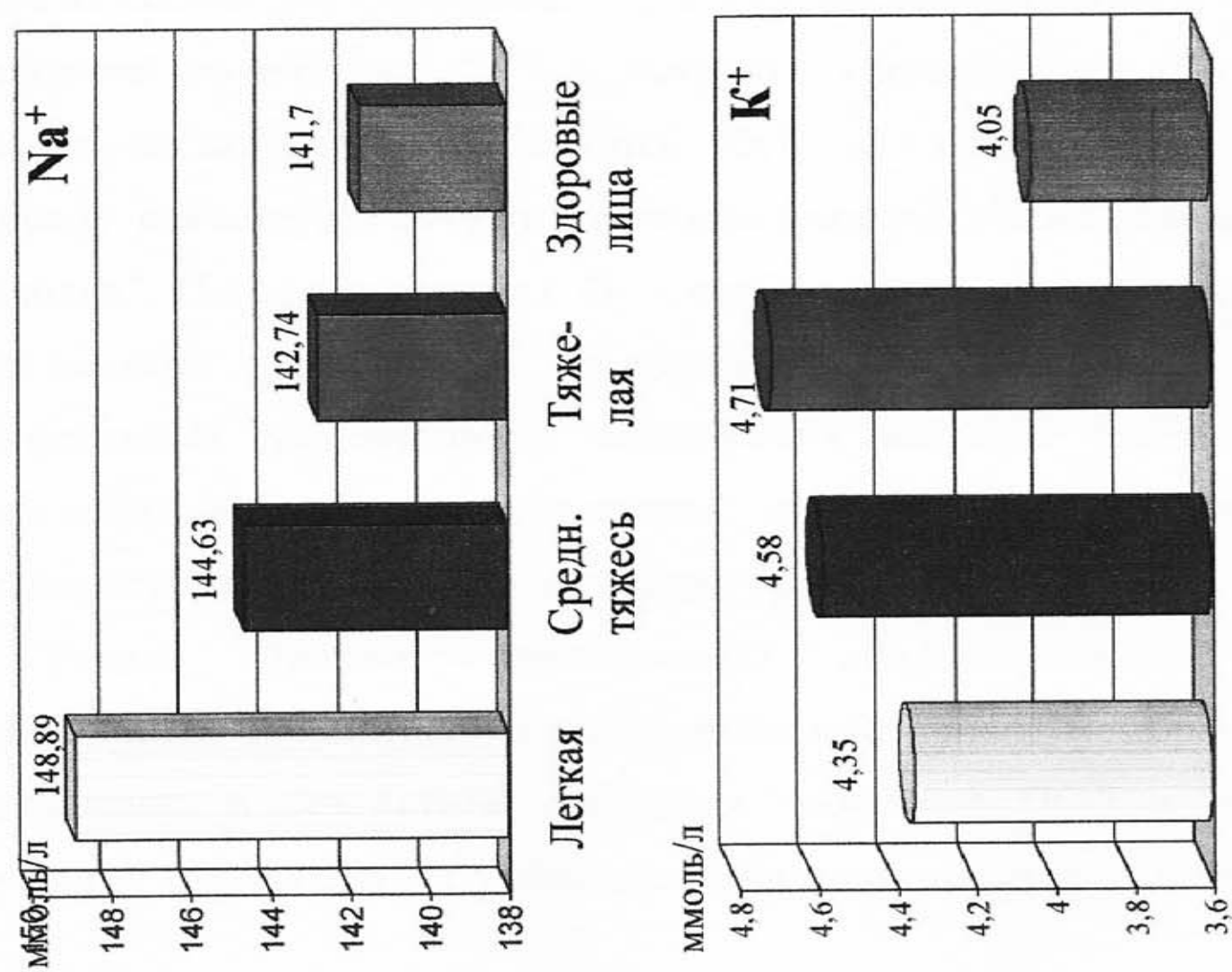

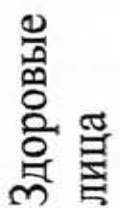

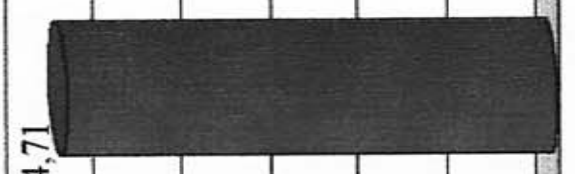

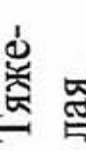

恶 总

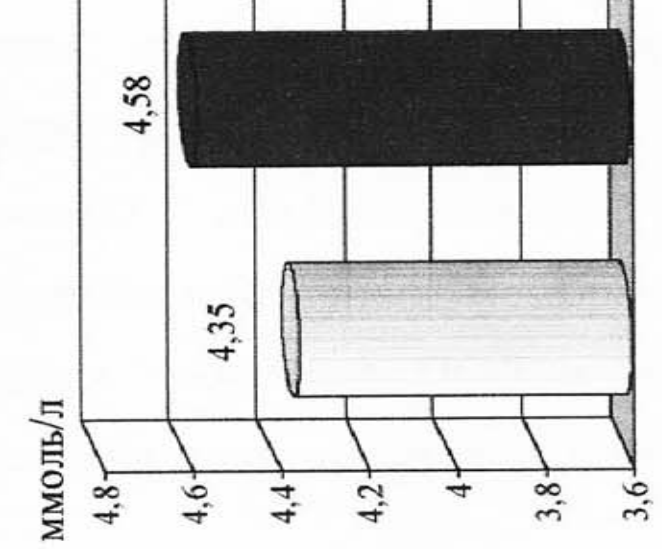

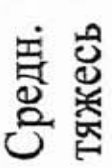

预 

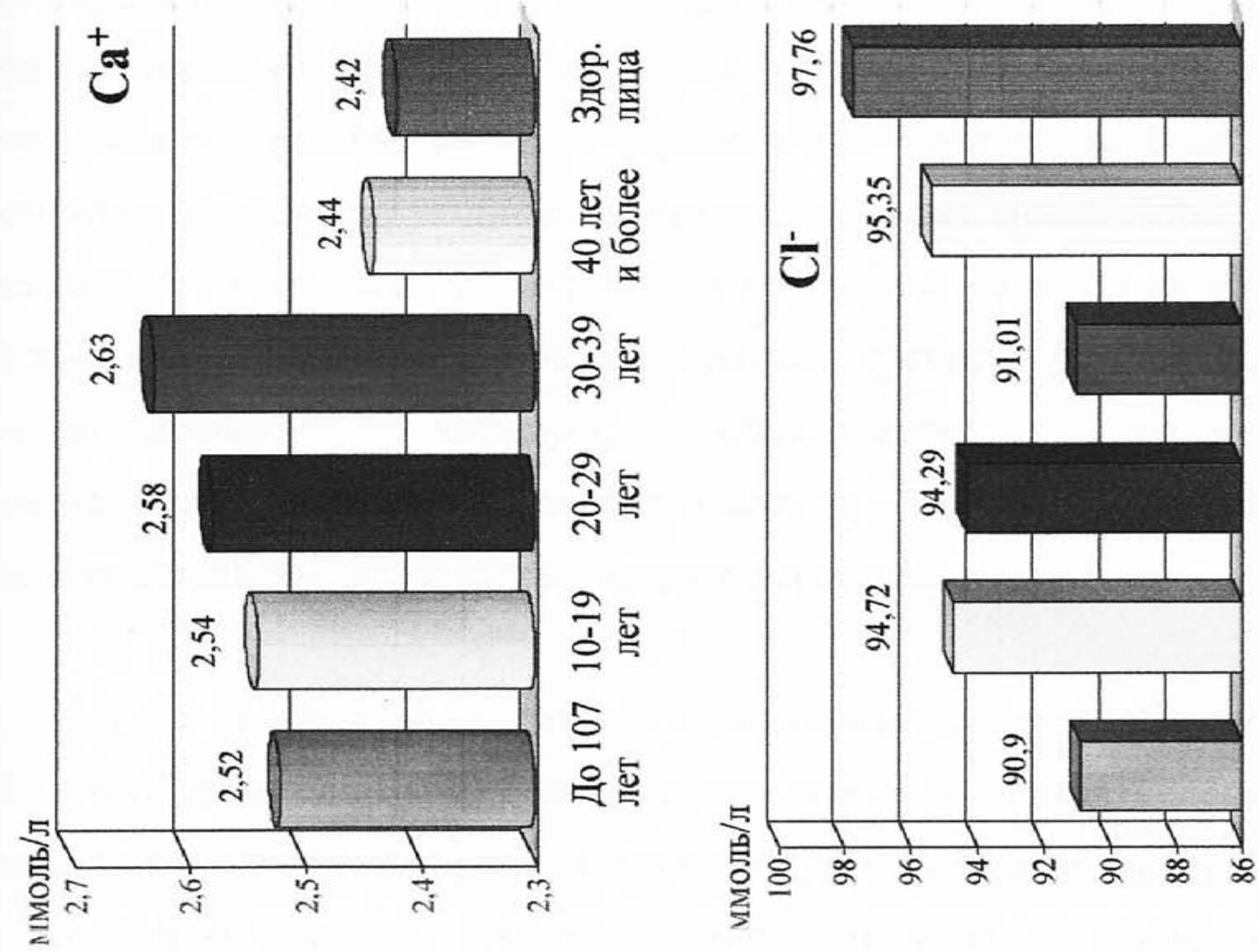

응 ్ㅗㅋ

ธัญ

लेष

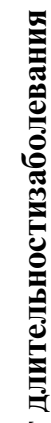

ते

으 흔

을혼
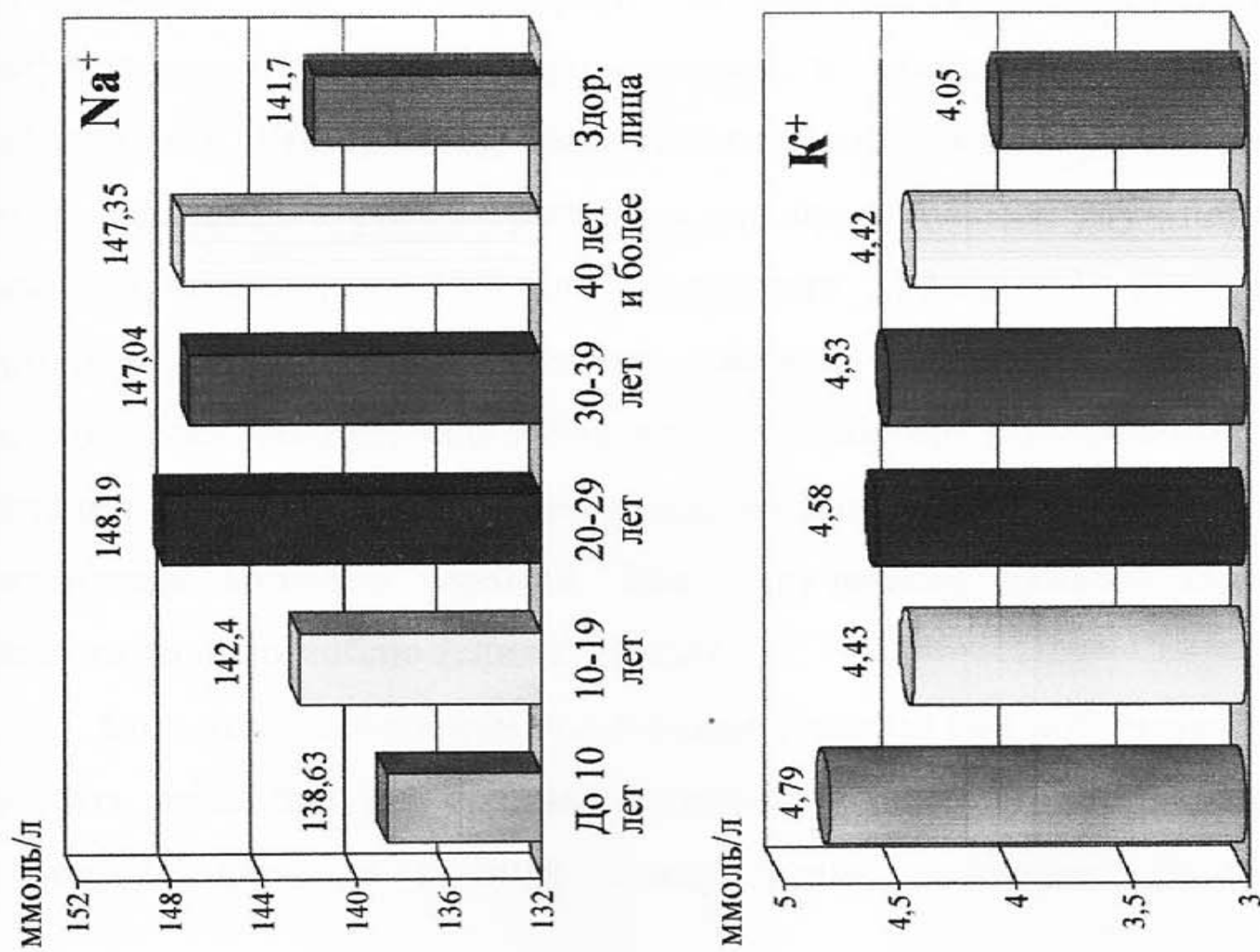

官 ్ㅠㄹ

志莺

केष्ट

तें

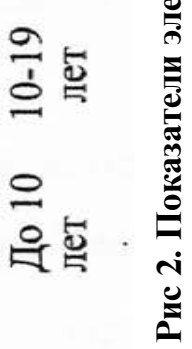


количества натрия соответственно на 5,1\% и 2,1\%, а количество кальция при средней и тяжелой степени заболевания увеличено соответственно, на 5,4\% и 7,9\%. Рис. 2 иллюстрирует характер изменения содержания электролитов натрия, калия, кальция и хлоридов в сыворотке крови больных миотонией в зависимости от длительности заболевания. Из представленных данных видно, что количество хлора в сыворотке крови больных с различной длительностью заболевания не отличается от показателей контрольной группы. Количество же калия у всех больных с различной длительностью заболевания статистически возрастает. Количество натрия и кальция статистически возрастают только в крови больных с наибольшей длительностью заболевания.

Как известно, содержание электролитов во внеклеточной жидкости, цитоплазме и внутриклеточных органеллах в физиологических условиях существенно различаются.

Ионная асимметрия - явление динамическое и зависит от функционального состояния клетки [6]. Нарушение барьерной функции мембран для одновалентных катионов и анионов связано с повреждением плазматической мембраны, осуществляющей регуляцию их содержания с помощью На+, К+ - АТ Фазы и На+ /Ьа2+ - обменной системы $[8,9]$

Нарушения барьерной функции мембран

\section{СПИСОК ЛИТЕРАТУРЫ}

Арчаков А.И., Мохосов И.М. Модификация белков активным кислородом и их распад. Биохимия, 1989, № 2, с. 179-185

Афанасьев И.Б. Кислородные радикалы в биологических процессах. Хим. фарм. журн., 1985, № 2, с. 11-23 Козлов Ю.П., Коган В.Е., Архипенко Ю.В. Молекулярные механизмы повреждения кислородом системы транспорта кальция в саркоплазматическом ретикулуме мышц. Иркутск, Изд-во Иркутс. Гос. Ун-та, 1983, 134 с

Backman E., Henriksson K.G. Treatment of congenital myotonia with sodium selenite and vitamin E. (Letter). J. Intern. Med., 1992, V.232, № 4, p. 376-377

Arieff A.I. Management of hyponatraemia. British Med. J; 1993, № 307, p. 305-308

6. Beck L.H. Body fluid and electrolyte disorders. The для двухвалентных катионов, в частности ионов Са2+, представляют собой наиболее тяжелые повреждения мембран. Системы, обеспечивающие гомеостаз клетки по двухвалентным ионам (Ca2+), локализуются в плазматической мембране, мембранах саркоплазматического ретикулума и внутренней мембране митохондрий. Показано, что центральными моментами в нарушении гомеостаза кальция в клетке являются два феномена: 1) увеличение содержания $\mathrm{Ca} 2+$ в цитоплазме; 2)повышение количества $\mathrm{Ca} 2+$ в матриксе митохондрий [3]. Явление избыточного транспорта $\mathrm{Ca} 2+$ из крови через плазматическую мембрану в клетку, а оттуда в митохондрии получило название «кальциевого парадокса».Он тесно связан с O2 - парадоксом и является одним из наиболее существенных признаков повреждения. Основными повреждающими воздействиями увеличенного содержания кальция считаются: нарушение энергетической функции митохондрий, активация фосфолипаз и арахидонового каскада, активация протеаз и агрегация тромбоцитов [11].

Таким образом, наблюдаемый энергетический дефицит среди молекулярных механизмов повреждения клеточных биомембран и связанные с этим нарушения электролитного обмена играют значимую роль в патогенетических механизмах при миотонии Томсена.

Medical Clinics of North America, 2003, № 65, p. 247-251 7. Becker P.E. Clinical-genetic studies of the nondystrophic myotonias. In: Myotonia congenita and syndromes associated with myotonia, Stuttgart, Thieme, 2002, p. 18-32

8. Gill G.V., Flear C.T. Hyponatraemia. Recent Advanced in Clinical Biochemistry, 1985, № 3, p. 149-159 9. Heath D., Marx. Calcium Disorders, London, Butternorth, 1982, p. 27-28

10. Ihara Y., Mori A., Hayabara T., Namba R., Nobukuni K., Sato K., Miyata S., Edamatsu R., Liu J., Kawai M. Free radicals, lipid peroxides and antioxidants in blood of patients with myotonic distrophy. J. Neurol., 1995, V.242, № 3, p. 119-122

11. Morgan D.B. Electrolyte disorders. Clinics in Endocrinology and Metabolism, 1984, № 13, p. 231-234 


\title{
XULASP
}

\section{TOMSEN MIOTONIYASININ PATOGENETIK MEXANIZMLORINDӘ ELEKTROLIT MÜBADİLOSINIIN ROLU}

\author{
${ }^{1}$ Hosənov X.İ., ${ }^{2}$ Oliyeva D.M., ${ }^{2}$ Quliyev M.R. \\ ${ }^{\prime}$ O. Oliyev adına Azərbaycan Dövlat Həkimlari Təkmillaşdirmə Institutu, Bakı \\ ${ }^{2}$ Azarbaycan Tibb Universiteti, Bakl
}

Tomsen miotoniyası ilə 40 xəstənin və 54 sağlam şəxsin qan zərdabında $\mathrm{Ca} 2+, \mathrm{Na}+, \mathrm{K}+$ və $\mathrm{Cl}-$ miqdarları öyənilmişdir. Müəyyən edilmişdir ki, qan zərdabında Cl- göstəricisi kontrol qrupla müqaisədə dəyişiksiz galir. Müxtəlif ağırlıq dərəcəsinə malik xəstələrin qan zərdabında K+ miqdarı statistik artır. Xəstəliyin yüngül dərəcəsində $\mathrm{K}+$ miqdarı, ağır dərəcəsində $\mathrm{Na}+$ və $\mathrm{Ca} 2+$ miqdarları kontrol qrupa görə statistik etibarlı yüksəlir. Alınan nəticələr Tomsen miotoniyasının patogenezində elektrolit mübadiləsinin mühüm rol oynadığını təsdiq edir.

Açar sözlər: Tomsen miotoniyası, elektrolit mübadiləsi.

\section{SUMMARY}

\section{THE ROLE OF THE ELECTROLYTES EXCHANGE ON PATHOGENESIS OF THOMSEN'S MYOTONIA}

\author{
${ }^{1}$ Hasanov Kh.I., ${ }^{2}$ Aliyeva D.M., ${ }^{2}$ Guliyev M.R. \\ ${ }^{1}$ Azerbaijan State Advanced Trainity Institute for Dostors named after A.Aliyev, Baku \\ ${ }^{2}$ Azerbaijan Medical University, Baku
}

In serum of the 40 patients and 54 healthy persons were determined electrolytes: $\mathrm{Ca} 2+, \mathrm{Na}+$, $\mathrm{K}+$ and $\mathrm{Cl}-$. At various degrees of weight of current Thomsen's myotonia in serum of the patients at the content of quantity of $\mathrm{Cl}-$, the quantity of $\mathrm{K}+$ statistically increases. At an easy degree of disease the increase in contents of $\mathrm{Na}+$ is observed at heavy $\mathrm{Ca} 2+$. The received data can testify the role of electrolytes exchange in the pathogenesis of Thomson's myotonia.

Key words: Thomsen's myotonia, electrolytes exchange.

Redaksiaya daxil olub: 18.09.2012

Çapa tövsiy olunub: 28.09 .2012

Rayçi: R.L.Hasənov, t.e.d. dosent 